\title{
Backward conditioning of the rabbit eyelid response: A test using second-order conditioning
}

\author{
STEVEN D. STERN and PETER W. FREY \\ Northwestern University, Evanston, Illinois 60201
}

\begin{abstract}
Investigations studying fear in the rat have reported that a CS paired in a backward relationship with the US can acquire excitatory properties. This procedure does not appear to be effective in rabbit eyelid conditioning. The present studies examined Rescorla's proposal that an excitatory effect might be observed with US-CS pairings in eyelid conditioning if the CS was tested in a second-order conditioning paradigm. The results provided no support for this proposal because second-order eyelid conditioning was just as difficult to demonstrate as was backward eyelid conditioning.
\end{abstract}

According to Pavlov (1927/1960, p. 27), the conditioned stimulus (CS) should begin to operate before the unconditioned stimulus (US) comes into action, if conditioning is to occur. With rabbit eyelid conditioning, the evidence indicates that backward pairings do not result in conditioned excitation (Plotkin \& Oakley, 1975; Siegel \& Domjan, 1971; Smith, Coleman, \& Gormezano, 1969; Holmes, Note 1). Examples in the conditioned suppression literature, however, demonstrate that US-CS pairings can result in conditioning (Heth, 1976; Heth \& Rescorla, 1973; Keith-Lucas \& Guttman, 1975; Mahoney \& Ayres, 1976).

Rescorla (Note 2) has suggested that the lack of overt responding after backward pairings in the eyelid preparation does not necessarily imply that the subject knows nothing about the relationship between the CS and the US. He stated (Rescorla, 1976) that "consequences of first-order conditioning which are not observed in the response to the first-order CS may nevertheless be observed in its ability to establish conditioning to higher order stimuli." Thus, he suggests that second-order conditioning may provide a more sensitive measure of what is learned from US-CS pairings.

\section{EXPERIMENT 1}

In this experiment, we examined the effects of US-CS pairings in rabbit eyelid conditioning. In addition to traditional measures of conditioning, we employed the second-order conditioning test suggested by Rescorla.

This report is based on a thesis submitted to the Graduate School of Northwestern University by the first author in partial fulfillment of the requirements for the MS degree. It was supported by NSF Grant BMS 75-02313, awarded to the second author. Requests for reprints should be directed to Steven Stern, Department of Psychology, Northwestern University, 2021 Sheridan Road, Evanston, Illinois 60201.

\section{Method}

Subjects. The subjects were 70 male rabbits, weighing approximately $1.8 \mathrm{~kg}$. Animals were housed individually and had free access to water and Purina Rabbit Chow. The colony was maintained at a temperature of $21^{\circ} \pm 2^{\circ} \mathrm{C}$ and $50 \%$ relative humidity $( \pm 15 \%)$. Automated overhead lights were on from 7:00 a.m. to 8:00 p.m. daily.

Apparatus. The rabbits were conditioned in a large, soundattenuated, lightproof walk-in chamber. Temperature and relative humidity were kept at $20^{\circ} \pm 1^{\circ} \mathrm{C}$ and $50 \% \pm 10 \%$, respectively. During conditioning, each animal was restrained in a Plexiglas stock (see Frey \& Gavin, 1975, Figure 1). A Grason-Stadler (Model 901B) noise generator maintained the background sound level at $72 \mathrm{~dB}$ SPL (re: $20 \mu \mathrm{N} / \mathrm{m}^{2}$ ).

When in the chamber, each rabbit wore a small Plexiglas platform to which was attached a 6-V bulb and photocell, positioned on an aluminum arm, approximately $2.5 \mathrm{~cm}$ from the rabbit's right eye. The amount of reflected light changed when the rabbit blinked, and this change was sensed by the photocell. A six-channel Beckman Instruments (504D) dynograph recorder graphically recorded eyelid movements. The CSs were a $3-\mathrm{kHz}$ tone (84 dB SPL) and a click produced by a 20-peaks/sec spike generator. The US was a $2.75-\mathrm{mA}$ constant-current ac shock.

Procedure. The rabbits were habituated to their cages for 2 days prior to surgery. In preparation for surgery, each animal received a .3-cc subcutaneous injection of atropine sulphate (Holmes Serum Company) and a .35-cc intramuscular injection of Innovar-Vet (Pitman-Moore, Inc.). Two electrodes (25-gauge stainless steel wire) for US delivery were placed in the cheek just below and to either side of the right eye. Two stainless steel bolts (2-56 x $12.7 \mathrm{~mm})$ were embedded in the skull on a diagonal, to the left and right of bregma, and rested on the dura. A third bolt $(2-56 \times 5 \mathrm{~mm})$ was placed to the left of bregma as an additional support for the covering layer of plastic modeling compound. The animal's skin was sutured over the plastic layer. A 2-day recovery period followed surgery.

All animals were given one session $(1 \mathrm{~h})$ of habituation to the shock and recording apparatus. Animals were then divided into six groups for first-order acquisition. Two groups received backward pairings of $\mathrm{CS}_{1}$ and the US with CS-US intervals of -300 (B-300) and -100 (B-100) msec. Two other groups received forward $\mathrm{CS}_{1}$-US pairings with CS-US intervals of 100 and $300 \mathrm{msec}$ (F-100, F-300, respectively). One group (S) was trained with the onset of CS and US occurring simultaneously. The sixth group (EU) received explicitly unpaired presentations 
of $\mathrm{CS}_{1}$ and the US. For all groups, CS duration was $300 \mathrm{msec}$ and US duration was 100 msec.

The click and the tone were counterbalanced as the firstorder $\left(\mathrm{CS}_{1}\right)$ and second-order $\left(\mathrm{CS}_{2}\right)$ stimuli. First-order training was carried out for six sessions of 40 trials each. The intertrial interval (ITI) was held constant at $90 \mathrm{sec}$ for all groups except $\mathrm{EU}$, for which it was set at $60 \mathrm{sec}$. This maintained the US density at an equivalent value for all groups during the secondorder conditioning stage.

Following first-order training, all animals received four 40trial sessions of second-order conditioning. Both stimuli were $300 \mathrm{msec}$ in duration, and the interstimulus interval was $300 \mathrm{msec}$. The ITI was set at $90 \mathrm{sec}$. First- and second-order trials were alternated. Popik, Stern, and Frey (Note 3) have shown that this intermixture procedure is more effective than other arrangements.

After second-order conditioning, a transfer-of-training test was employed. Forty forward pairings of the second-order CS with the US were given each day until each animal had made 10 CRs. The ITI was $90 \mathrm{sec}$ and the CS-US interval was $300 \mathrm{msec}$.

\section{Results and Discussion}

A conditional response (CR) was defined as a pen deflection of $1 \mathrm{~mm}$ or more in the direction involving eyelid closure and occurring during the CS or within $50 \mathrm{msec}$ of CS offset. This same criterion was used to define $\mathrm{CRs}$ to $\mathrm{CS}_{2}$ on the $\mathrm{CS}_{2}-\mathrm{CS}_{1}$ trials. The gain control of the recording system was adjusted such that a complete eyelid closure caused a pen deflection of 20-25 mm.

Two measures of conditioning to the first-order CS $\left(\mathrm{CS}_{1}\right)$ are presented in Table 1. The first was the number of CRs to $\mathrm{CS}_{1}$ on the last day of first-order training. The second measure was the number of CRs to $\mathrm{CS}_{1}$ on the $\mathrm{CS}_{2}-\mathrm{CS}_{1}$ trials of the first day of second-order conditioning. The results for the first measure indicated that F-300 produced more CRs than F-100 (77.3\% vs. $2.6 \%$, respectively. A Mann-Whitney $U$ test showed this difference to be reliable $[U=0, p<.05]$. No data were available on this measure for Groups S, B-100, or B-300. The second measure provided an equal response interval for each group. Because $\mathrm{CS}_{2}$ always precedes $\mathrm{CS}_{1}$, however, the response measure may be compromised by external inhibition or stimulus generalization decrement. On this measure, both F-300 and F-100 showed some evidence of excitatory conditioning to $\mathrm{CS}_{1}$. F-300 and F-100 responded on $36.7 \%$ and $4.2 \%$ of the trials, respectively. Mann-Whitney comparisons indicated that
F-300 differed from all other groups [U $=19, p<.05]$ and that there were no other differences. Our failure to find conditioned responding in the simultaneous and backward groups is in agreement with previous eyelid studies (Plotkin \& Oakley, 1975; Siegel \& Domjan, 1971; Smith et al., 1969; Holmes, Note 1).

Second-order conditioning was examined by counting the total number of $\mathrm{CRs}$ to $\mathrm{CS}_{2}$ during the 4 days of second-order training. Since the second-order association depends on the strength of the first-order association, this measure provides Rescorla's additional assessment of the first-order treatments. Each group had an equal response interval $(300 \mathrm{msec})$ and, as $\mathrm{CS}_{2}$ always preceded $\mathrm{CS}_{1}$, there was no contamination from external inhibition.

As presented in Table 1, F-300 had the highest number of second-order CRs to $\mathrm{CS}_{2}$ on the $80 \mathrm{CS}_{2}-\mathrm{CS}_{1}$ trials (7.1\%). F-100 responded to $\mathrm{CS}_{2}$ on $1.5 \%$ of the trials, and the group having the CS and US unpaired (EU) during the first phase had a response rate of $.8 \%$. No second-order CRs were observed in the other groups. Mann-Whitney comparisons of the response rates to $\mathrm{CS}_{2}$ indicated that F-300 differed from F-100 ( $p<.05$ ) and that F-100 was not different from any of the other groups. These data suggest that, if any excitatory conditioning took place as a result of the backward pairings of $\mathrm{CS}_{1}$ and the US, it was not reflected in the animal's second-order conditioning performance. This outcome does not support Rescorla's hypothesis that a secondorder procedure might provide evidence for backward conditioning of the eyelid response.

Following the second-order conditioning phase, all subjects were given a transfer test in which the secondorder CS $\left(\mathrm{CS}_{2}\right)$ was paired with the US at a $300-\mathrm{msec}$ interstimulus interval. The pairings continued in daily sessions of 40 trials until each rabbit had made at least 10 CRs. The dependent measure was the number of $\mathrm{CS}_{2}$-US pairings required to produce $10 \mathrm{CRs}$. As indicated in the table, F-300 achieved this criterion in 44.8 trials, while F-100 required 161.7 trials. Acquisition of responding to $\mathrm{CS}_{2}$ was reliably influenced by first-order treatments $[F(5,58)=10.4, p<.05]$, and a NewmanKeuls test indicated that F-300 reached this criterion faster than all other groups. This outcome provides no

Table 1

Several Measures of the Associative Strength of $\mathrm{CS}_{1}$ and $\mathrm{CS}_{2}$ in Experiment 1

\begin{tabular}{|c|c|c|c|c|c|c|}
\hline & EU & B300 & $\mathrm{B} 100$ & $\mathbf{S}$ & $\mathrm{F} 100$ & F300 \\
\hline $\begin{array}{l}\text { Mean response rate* to } \mathrm{CS}_{1} \text { on } \mathrm{CS}_{1}-\mathrm{US} \text { trials on the } \\
\text { last day of first-order training }\end{array}$ & 0.4 & & & & 2.6 & 77.3 \\
\hline $\begin{array}{l}\text { Mean response rate* to } \mathrm{CS}_{1} \text { on the } \mathrm{CS}_{2}-\mathrm{CS}_{1} \text { trials on } \\
\text { Day } 1 \text { of second-order conditioning }\end{array}$ & 0.4 & 0.8 & 0.0 & 0.8 & 4.2 & 36.7 \\
\hline Mean response rate* to $\mathrm{CS}_{2}$ during second-order training & 0.8 & 0.0 & 0.0 & 0.0 & 1.5 & 7.1 \\
\hline $\begin{array}{l}\text { Proportion of subjects making two or more } \mathrm{CRs} \text { to } \mathrm{CS}_{2} \\
\text { during the second-order conditioning phase }\end{array}$ & $1 / 11$ & $0 / 12$ & $0 / 11$ & $0 / 12$ & $3 / 12$ & $10 / 12$ \\
\hline Mean trial of the 10 th $\mathrm{CR}$ to $\mathrm{CS}_{2}$ on transfer test & 244.27 & 238.5 & 209.36 & 220.17 & 161.67 & 44.75 \\
\hline
\end{tabular}


new evidence in support of excitatory backward conditioning. If backward conditioning had an inhibitory effect, Groups B-300 and B-100 would require more trials to meet criterion in the transfer test than Group $S$. The absence of this outcome suggests that the backward pairings did not produce an inhibitory $\mathrm{CS}$.

\section{EXPERIMENT 2}

Experiment 1 produced only marginal evidence of second-order conditioning when forward first-order pairings were employed. Previous experiments in this laboratory directly compared eyelid and fear responses and observed that second-order fear conditioning was much more robust than second-order eyelid conditioning (Maisiak \& Frey, 1977; Popik et al., Note 3). It is noteworthy that the difference in backward conditioning for the two response systems seems to be paralleled by a similar difference in second-order conditioning. Experiment 2 was designed to determine if reliable second-order conditioning can be established with the eyeblink paradigm.

\section{Method}

Subjects. Twenty male albino rabbits were housed and fed as in the first experiment.

Apparatus. The equipment was identical to that of Experiment 1, except for the location of the click CS. In the first study, the click, tone, and noise were presented from speakers in front of the rabbits. In this study, the tone and noise were presented from speakers suspended from the ceiling of the chamber, and the click from a speaker in front of each rabbit. Click and tone intensity were $82 \mathrm{~dB}$ SPL and the white-noise background was presented at $72 \mathrm{~dB}$ SPL (re: $20 \mu \mathrm{N} / \mathrm{m}^{2}$ ).

Procedure. Surgery and habituation were carried out as before. In Phase 1, all animals received six sessions of $\mathrm{CS}_{1}$-US pairings. The CS was a $300-\mathrm{msec} 3-\mathrm{kHz}$ tone or a $20-\mathrm{peak} / \mathrm{sec}$ click; the US was a 100 -msec $2.75-\mathrm{mA}$ constant-current shock. The tone and the click were counterbalanced as $\mathrm{CS}_{1}$ and $\mathrm{CS}_{2}$. The ITI was $90 \mathrm{sec}$, and there were 40 trials per session.

Phase 2 began with the seventh conditioning session and continued for four sessions. Half the subjects $(\mathrm{F} 3 \mathrm{P})$ received 20 $\mathrm{CS}_{1}$-US trials alternated with 20 second-order $\mathrm{CS}_{2}-\mathrm{CS}_{1}$ trials in each session. The ITI was $90 \mathrm{sec}$ and the interstimulus interval was $300 \mathrm{msec}$. The remaining subjects (F3U) received a sequence of $\mathrm{CS}_{1}-\mathrm{US}, \mathrm{CS}_{2}$-alone, and $\mathrm{CS}_{1}$-alone trials at an ITI of $60 \mathrm{sec}$. There were 60 trials per session.

A transfer-of-training test was initiated on Session 11. All animals received pairings of the second-order CS and the US in daily sessions of 40 trials until each animal had made $10 \mathrm{CRs}$ to $\mathrm{CS}_{2}$. The ITI was $90 \mathrm{sec}$, and the CS-US interval was $300 \mathrm{msec}$.

\section{Results and Discussion}

An examination of the first-order CRs on Day 6, the last session of Phase 1, indicated a response rate of $85 \%$ for F3P and $89 \%$ for $F 3 U[F(1,19)=1.09]$. Response rates to $\mathrm{CS}_{2}$ were examined on the last day of Phase 2 . The paired group, F3P, made an average of 3.2 CRs to $\mathrm{CS}_{2}$ (i.e., 16\%). The unpaired group, F3U, made an average of $2.2 \mathrm{CRs}$, a response rate of $11 \%$. This difference was not significant $[F(1,19)<1]$. The transfer test provided no additional evidence of second-order conditioning. F3P required a mean of 18.2 trials to make
$10 \mathrm{CRs}$ to $\mathrm{CS}_{2} ; \mathrm{F} 3 \mathrm{U}$ required 22.4 trials. The difference was not significant $[\mathrm{F}(1,19)<1]$.

The results of Experiment 2 indicate that little, if any, second-order eyeblink conditioning occurs with the conditioning parameters used in this study. Group F3P, which had conventional second-order trials, did not respond at a rate significantly higher than that of $\mathrm{F} 3 \mathrm{U}$, which had $\mathrm{CS}_{2}$ and $\mathrm{CS}_{1}$ in an unpaired relationship.

\section{GENERAL DISCUSSION}

The present investigation found no evidence for backward eyelid conditioning. In this respect, the results are consistent with previous studies which investigated US-CS pairings with the eyeblink response (Plotkin \& Oakley, 1975; Siegel \& Domjan, 1971; Smith et al, 1969; Holmes, Note 1). The second-order conditioning test employed, as Rescorla (Note 2) suggested, did not provide evidence for either backward conditioning or secondorder conditioning with this preparation.

There are a number of potential explanations for this outcome. The absence of backward conditioning in our study and in previous studies may be due to the relationship between the duration of the CS and the ITI. Eyelid conditioning customarily employs durations of $1 / 2 \mathrm{sec}$ or less and ITIs of $60 \mathrm{sec}$ or more. All backward eye conditioning investigations have followed this pattern. Moscovitch and LoLordo (1968) report, however, that a backward CS is more likely to gain inhibitory properties in fear conditioning when the ITI is much longer than the duration of the CS. It is not clear, however, that a massed trials procedure would facilitate backward eyelid conditioning, because forward eyelid conditioning suffers when a massed trial procedure is employed (Frey \& Misfeldt, 1967). There is no reason to expect that this deleterious influence would not also be present in backward conditioning.

Another potential explanation for the lack of backward conditioning in these studies is based on the report (Heth, 1976; Keith-Lucas \& Guttman, 1975) that excitatory fear conditioning is present after a small number of US-CS pairings. Subsequent US-CS pairings seem to have an inhibitory effect. Eyelid conditioning generally requires many more CS-US pairings than fear conditioning and this procedure has been continued in the backward eyelid conditioning studies. The smallest number of US-CS pairings was 90 (Holmes, Experiment 1, Note 1) and the largest number was 640 (Smith et al., 1969). Since several of the eyelid studies included CS-alone test trials during acquisition, the presence of overt CRs after a few US-CS pairings would have been detected. It is possible, however, that a more sensitive measure, such as a transfer test, might have provided evidence for excitatory conditioning if the test had been given after a small number of US-CS pairings. This is not very probable, however, because a small number of pairings is inadequate for demonstrating forward eyelid conditioning. It seems unlikely that a less robust phenomenon, such as backward conditioning, could be observed with the eyelid response after only a few trials.

In examining Rescorla's proposal that second-order conditioning might provide a more sensitive test for excitatory effects in backward conditioning, we not only failed to confirm his proposal, but discovered that second-order conditioning was difficult to demonstrate with the eyelid preparation. It is unlikely that our failure with second-order conditioning resulted from the selection of inappropriate conditioning parameters. Previous experiments in our laboratory have established that second-order conditioning is optimal when second- and firstorder trials are alternated within each training session (Popik et al., Note 3) and when the second-order CS terminates at the onset of the first-order CS (Maisiak \& Frey, 1977; Popik et al., Note 3). These arrangements were employed in both Experiments 1 and 2 . In addition, second-order eyelid conditioning 
has been systematically examined and there has been little evidence of stable CRs under conditions which produce robust second-order fear conditioning (Maisiak \& Frey, 1977; Popik et al., Note 3 ).

A more plausible explanation for the present results is that there are basic differences between the eyelid response and the fear response and that this response system factor is responsible for the different outcomes in both backward and second-order conditioning. One potential factor, in this regard, is that the eyeblink is a discrete, precisely timed response, while fear is more tonic in nature. Sears and Frey (Experiment 3, Note 4) have demonstrated that a CS in eyeblink conditioning elicits a CR at the point in time when a US is expected. In paradigms in which the CS does not overlap the US, the eyelid CR will not generally be initiated during the CS. This response system characteristic is not conducive to the occurrence of overt CRs to a secondorder or backward CS.

Another factor which may be relevant is that the eyelid response appears to require many more CS-US pairings than the fear response before stable conditioning is observed Schneiderman (1972) has suggested that response systems may differ in their threshold for responding. It is possible that secondorder conditioning and backward conditioning produce an intermediate level of associative strength which is above the threshold for the fear system, but below threshold for the eyeblink response.

It is not clear which of these interpretations is more appropriate. The response timing and threshold notions imply that a single associative process is involved in these outcomes, but that different response mapping rules apply within each system. It is also possible that each response system has its own unique associative process. A systematic analysis of these alternatives would be of considerable interest.

\section{REFERENCE NOTES}

1. Holmes, J. D. Effects of backward pairings of the CS and the US on classical conditioning of the nictitating membrane response in the rabbit. PhD dissertation, University of Iowa, 1971.

2. Rescorla, R. A. "Second Order Conditioning." Invited address, 48th annual meeting of the Midwestern Psychological Association, Chicago, May 1976.

3. Popik, R. S., Stern, S. D., \& Frey, P. W. Second-order conditioning: The interstimulus interval and the procedure for intermixing first-order and second-order trials. Unpublished manuscript.

4. Sears, R. J., \& Frey, P. W. The eyeblink as a time-locked response: Implications for serial and second-order conditioning. Unpublished manuscript.

\section{REFERENCES}

Frey, P. W., \& Gavin, W. Overnight incubation of a partially conditioned eyeblink response in rabbits. Animal Learning \& Behavior, 1975, 3, 114-118.

Frey, P. W., \& Misfeldt, T. J. Rabbit eyelid conditioning as a function of the intertrial interval. Psychonomic Science, 1967, 9, $137-138$

Heth, C. D. Simultaneous and backward fear conditioning as a function of number of CS-US pairings. Journal of Experimental Psychology: Animal Behavior Processes, 1976, 2, 117-129.

Heth, C. D., \& Rescorla, R. A. Simultaneous and backward fear conditioning in the rat. Journal of Comparative and Physiological Psychology, 1973, 82, 434-443.

Keith-Lucas, T., \& Guttman, N. Robust single-trial delayed backward conditioning. Journal of Comparative and Physiological Psychology, 1975, 88, 468-476.

Mahoney, W. J., \& Ayres, J. J. B. One-trial simultaneous and backward fear conditioning as reflected in conditioned suppression of licking in rats. Animal Learning \& Behavior, 1976, 4, 357-362.

MaisiaK, R., \& Frey, P. W. Second-order conditioning: The importance of stimulus overlap on second-order trials. Animal Learning \& Behavior, 1977, 5, 309-314.

Moscovitch, A., \& LoLordo, V. Role of safety in the Pavlovian backward fear conditioning procedure. Journal of Comparative and Physiological Psychology, 1968, 66, 673-678.

Pavlov, I. P. Conditioned reflexes. (Trans. by G. V. Anrep) New York: Dover, 1960. (Originally published, 1927.)

Plotkin, H. C., \& OAKLey, D. A. Backward conditioning in the rabbit. Journal of Comparative and Physiological Psychology, 1975, 88, 586-590.

Rescorla, R. A. Second order conditioning of Pavlovian conditioned inhibition. Learning and Motivation, 1976, 7, 161-172.

SChNeIderman, N. Response system differences in aversive classical conditioning. In F. Black \& W. F. Prokasy (Eds.), Classical conditioning: II. Current research and theory. New York: Appleton-Century-Crofts, 1972.

Siegel, S., \& Doman, M. Backward conditioning as an inhibitory procedure. Learning and Motivation, 1971, 2, 1-11.

Smith, M. C., Coleman, S. R., \& Gormezano, I. Classical conditioning of the rabbit's nictitating membrane response at backward, simultaneous and forward CS-US intervals. Journal of Comparative and Physiological Psychology, 1969, 69, 226-231.

(Received for publication December 27, 1977.) 